\title{
Winter and summer time size distributions and densities of traffic-related aerosol particles at a busy highway in Helsinki
}

\author{
A. Virtanen ${ }^{1}$, T. Rönkkö ${ }^{1}$, J. Kannosto ${ }^{1}$, J. Ristimäki ${ }^{1}$, J. M. Mäkelä ${ }^{1}$, J. Keskinen ${ }^{1}$, T. Pakkanen ${ }^{2}$, R. Hillamo ${ }^{2}$, \\ L. Pirjola ${ }^{3,5}$, and K. Hämeri ${ }^{4,5}$ \\ ${ }^{1}$ Tampere University of Technology, Institute of Physics, Aerosol Physics, P.O. Box 692, 33101 Tampere, Finland \\ ${ }^{2}$ Finnish Meteorological Institute, Air Quality Research, Sahaajankatu 20 E, 00810 Helsinki, Finland \\ ${ }^{3}$ Helsinki Polytechnics, Department of Technology, P.O. Box 4020, 00099 Helsinki, Finland \\ ${ }^{4}$ Finnish Institute of Occupational Health, Department of Physics, Topeliuksenkatu 41, 00250 Helsinki, Finland \\ ${ }^{5}$ University of Helsinki, Department of Physical Sciences, P.O. Box 64, 00014 University of Helsinki, Finland
}

Received: 23 September 2005 - Published in Atmos. Chem. Phys. Discuss.: 12 January 2006

Revised: 7 April 2006 - Accepted: 15 May 2006 - Published: 29 June 2006

\begin{abstract}
Number concentrations and size distributions of traffic related aerosol particles were measured at a roadside in Helsinki during two winter campaigns (10-26 February 2003, 28 January-12 February 2004) and two summer campaigns (12-27 August 2003, 6-20 August 2004). The measurements were performed simultaneously at distances of $9 \mathrm{~m}$ and $65 \mathrm{~m}$ from the highway. Total number concentrations were measured by a condensation particle counter (CPC) and particle size distributions by a scanning mobility particle sizer (SMPS) and an electrical low pressure impactor (ELPI). This study concentrates on data that were measured when the wind direction was from the road to the measurement site. The total concentrations in the wintertime were 2-3 times higher than in the summertime and the concentrations were dominated by nucleation mode particles. The particles smaller than $63 \mathrm{~nm}$ (aerodynamic diameter) constituted $\sim 90 \%$ of all particles in the wintertime and $\sim 80 \%$ of particles in the summer time. The particle total concentration increased with increasing traffic rate. The effect of traffic rate on particles smaller than $63 \mathrm{~nm}$ was stronger than on the larger particles. The particle distributions at the roadside consisted of two distinguishable modes. The geometric mean diameter (GMD) of nucleation mode (Mode 1) was $20.3 \mathrm{~nm}$ in summer and $18.9 \mathrm{~nm}$ in winter. The GMD of the larger mode consisting mostly of traffic related soot particles (Mode 2) was $72.0 \mathrm{~nm}$ in summer and $75.1 \mathrm{~nm}$ in winter. The GMD values of the modes did not depend on the traffic rate. The average particle density for each mode was determined by a parallel density fitting method based on the size distribution measurement made by ELPI and SMPS. The average density value for Mode 1 particles
\end{abstract}

Correspondence to: A. Virtanen

(annele.virtanen@tut.fi) was $1.0 \pm 0.13 \mathrm{~g} / \mathrm{cm}^{3}$ and $1.0 \pm 0.07 \mathrm{~g} / \mathrm{cm}^{3}$ both in summer and winter respectively, while the average density value for Mode 2 was $1.5 \pm 0.1 \mathrm{~g} / \mathrm{cm}^{3}$ and $1.8 \pm 0.3 \mathrm{~g} / \mathrm{cm}^{3}$ for summer and winter, respectively.

\section{Introduction}

Traffic is one of the most significant sources of fine particles in an urban environment. This has been shown earlier in many studies mostly based on measurements of the particle mass concentration. Recently, also the number concentration of fine particles measured at an urban background has been related to the traffic rate (Van Dingenen et al., 2004; Hussein et al., 2004). The size and concentrations of traffic related particles at roadsides have been widely studied during recent years.

Based on results obtained from number distribution measurements in engine or vehicle test laboratories, the fine particles in a vehicle exhaust are often distributed into two modes. The larger particle mode (number based geometric mean diameter $40-100 \mathrm{~nm}$ ) in the vehicle exhaust consists of soot particles and volatile materials condensed on them (Kittelson et al., 2000; Harris and Maricq, 2001). These soot particles are agglomerates formed in the engine during the combustion process. The soot particles are emitted mainly from diesel vehicles, whereas gasoline engines emit less soot (Harris and Maricq, 2001). Additionally, soot particles have been observed to be emitted from new technology gasoline direct injection vehicles (e.g. Harris and Maricq, 2001). The nucleation mode particles $(<30 \mathrm{~nm}$ in size) are liquid particles consisting mainly of hydrocarbons, water and sulphates (Kittelson, 1998; Khalek et al., 2000). The nucleation mode particles form during dilution and cooling of the exhaust which

Published by Copernicus GmbH on behalf of the European Geosciences Union. 
happen both in the laboratory and in the atmosphere (AbdulKhalek, 1999; Kittelson et al., 2000).

Chase studies of individual vehicles form a link between laboratory emission and roadside concentration measurements. Chase studies of diesel vehicles have been reported by Kittelson et al. (2000, 2004); Vogt et al. (2003); Giechaskiel et al. (2005); and Rönkkö et al. (2006). According to Kittelson et al. (2000) and Giechaskiel et al. (2005) the soot particle mode shows good agreement between the laboratory and on-road measurements. In the study of particle emissions of the diesel passenger car (Giechaskiel et al., 2005) the appearance of nucleation mode in the laboratory was similar to the on-road measurements, but the size of the particles were larger in the laboratory due to the lower dilution ratios. For a heavy duty vehicle, Rönkkö et al. (2006) found higher nucleation mode concentrations during the chase than in the laboratory, but reported similar behavior as a function of engine load. The nucleation mode formation takes place immediately after the exhaust has been emitted from tail pipe. According to Rönkkö et al. (2006) the nucleation mode was completely formed within $0.5 \mathrm{~s}$ of the emission into the atmosphere. The nucleation process is at present qualitatively understood, but the details are not known.

The size distribution characteristics measured at the roadside locations differ somewhat from those measured for single vehicles. According to Imhof et al. (2005a); Janhäll et al. (2004); Ketzel et al. (2004) and Wåhlin et al. (2001) the size distributions measured at the roadside were dominated by nucleation mode particles with a relatively constant peak size of $20 \mathrm{~nm}$. In laboratory and chase measurements the nucleation mode existence and peak diameter show great variation (Kittelson et al., 2004; Vaaraslahti et al., 2004; Rönkkö et al., 2006). The geometric standard deviation (GSD) of the nucleation mode measured in the engine laboratory is typically around 1.3-1.7. The roadside nucleation modes represent typically the broader end of the range. Imhof et al. (2005b) measured particle size distributions in two different road tunnels in Graz and Liverpool. They found a nucleation mode with GMD around $15-20 \mathrm{~nm}$ in Graz and $25 \mathrm{~nm}$ in Liverpool and GSDs approximately 1.8 and 1.5 , respectively.

Particle density is a physical property that carries information about particle composition and therefore about the origin of the particles and the processes they have experienced. Diesel soot particles are agglomerates with a size dependent density which is below $1 \mathrm{~g} / \mathrm{cm}^{3}$ for particles larger than $\sim 60 \mathrm{~nm}$ (Park et al., 2003; Virtanen et al., 2004b; Maricq et al., 2004). According to authors' knowledge, there are no density values available from roadside measurements, and only very limited amount from urban measurement sites. For particles $\leq 100 \mathrm{~nm}$, Stein et al. (1994) report values between 1.60 and $1.79 \mathrm{~g} / \mathrm{cm}^{3}$ and McMurry et al. (2002) between 1.35 and $1.7 \mathrm{~g} / \mathrm{cm}^{3}$. According to authors' knowledge, density values for urban aerosol particles in the size range of nucleation mode have not been reported.
As fine particle sources, different individual vehicles (heavy-duty vehicles, diesel cars, petrol cars etc.) running on different kinds of fuel have a variety of emission profiles. The particulate matter emitted from traffic is a mixture of primary particles directly from different vehicle sources and secondary particles formed after gas phase emission via gas-to-particle conversion. The relationship between primary (or secondary) particulate emissions from individual vehicles and the particulate emissions from the whole road is not extremely well understood. The number distributions measured at these two cases seem to slightly differ from each other. This is partly because a mixture of sources is observed at the roadside, but also partly because several fundamental processes such as nucleation, evaporation/condensation, coagulation, internal conversion in the particle phase etc. take place under real conditions. Especially the nucleation process in the atmosphere may not be exactly identical with the process observed in laboratory. Due to the external mixing process, also the characteristics of the particle modes and also particle density may differ from those measured for individual vehicles. We believe that there is still need for detailed particle characterization at the roadside as well as for detailed analysis of the whole particulate emissions from the traffic source.

In this paper, we present results of a roadside measurement campaign. The concentration of different sized particles as well as the median sizes of modes measured at the roadside is related to the traffic rate. This is important, when the dependence of the concentration of different sized particles or mode characteristics on source parameters, such as traffic rate, need to be known. Also the differences between the emissions during the winter and summer time are studied. Especially, the characteristics of modes appearing in measured particle size distributions at the roadside are investigated. In addition, the average density of particles in modes will be estimated, including the nucleation mode.

\section{Description of measurement campaign}

\subsection{Measurement site description}

The measurement site was located in the Herttoniemi district of Helsinki, some $6 \mathrm{~km}$ east from the city centre. The investigated highway (Itäväylä) is the main road towards northeast from city centre (Fig. 1). The highway consists of 3 lanes in both directions. The measurements were part of the Finnish project LIPIKA ("Relationship of traffic related fine particle emissions to engine laboratory measurements") and they were performed during 4 campaigns. Two winter campaigns took place in 10-26 February 2003 and 28 January12 February 2004, and two summer campaigns in 12-27 August 2003 and 6-20 August 2004. Simultaneous measurements were made at distances of $9 \mathrm{~m}$ and $65 \mathrm{~m}$ from the nearest edge of the highway. The instruments were stationed in 
two similar cabins, sampling at $5.7 \mathrm{~m}$ above ground level. The sampling lines were identical in both cabins. A sample flow of 16 liters per minute was fed through cabin roof with a $3 \mathrm{~m}$ long sampling tube, $25 \mathrm{~mm}$ in diameter. A Minnesota type pre-cutting separator with $10 \mu \mathrm{m}$ cut diameter was used as a pre-cutter. The sampling lines included two $90^{\circ}$ bends, but the inertial losses caused by them are regarded insignificant for the sub micrometer particle measurements reported in this paper. The diffusion losses in sampling lines were calculated for the investigated size range. Losses for particles larger than $10 \mathrm{~nm}$ in diameter were less than $5 \%$. Diffusion losses for particles larger than $100 \mathrm{~nm}$ were negligible: less than $1 \%$. Due to the similarity of the sampling lines the results gained at $9 \mathrm{~m}$ and $65 \mathrm{~m}$ distance from the road are believed to be comparable.

A factory is located next to the measurement site $(35 \mathrm{~m}$ to north from the $65 \mathrm{~m}$ cabin). Its emissions were clearly distinguishable from traffic emissions (strong concentration peak at $30 \mathrm{~nm}$ ). Based on the measured wind direction, the data with wind direction directly from the factory towards the measurement site were omitted.

\subsection{Instrumentation}

The total number concentrations at the roadside were measured with a condensation particle counter (CPC, TSI, model 3025). The detection limit of CPC 3025 is $3 \mathrm{~nm}$. Because of high particle concentrations especially during the rush hours, a passive diluter with a dilution ratio of $\sim 1: 4$ 1:6 was used in CPC measurements. The average and maximum and minimum values for particle number concentration, measured by CPC, were recorded every five seconds. During the campaigns in 2004 a Scanning Mobility Particle Sizer designed for nano particles (referred further as "nanoSMPS") equipped with nano-DMA (TSI, model 3085) and CPC 3025 was used in the $9 \mathrm{~m}$ cabin (measurement range $3 \mathrm{~nm}-57 \mathrm{~nm}$ ). Scanning Mobility Particle Sizer (referred further as "long-SMPS") with DMA model 3071 and CPC 3025 was used in the $65 \mathrm{~m}$ cabin during all campaigns. The "longSMPS“ measurement range covered the particles from $5 \mathrm{~nm}$ to $160 \mathrm{~nm}$. An Electrical Low Pressure Impactor (ELPI, Dekati Ltd) with filter stage was used in both cabins, covering the particle size range of $7 \mathrm{~nm}-6.6 \mu \mathrm{m}$. It should be noted that ELPI measures the aerodynamic size of the particles. Particle number concentrations discussed below were measured at $9 \mathrm{~m}$. The data measured in the $65 \mathrm{~m}$ cabin are used only to study the evolution of size distribution and particle density.

In addition to stationary measurement sites, a mobile measurement unit, "Sniffer" (Pirjola et al., 2004), was used in the background concentration measurements. The urban background concentrations were measured at Saunalahti, $600 \mathrm{~m}$ northwest from the measurement site. The background particle concentrations were measured using SMPS and ELPI.

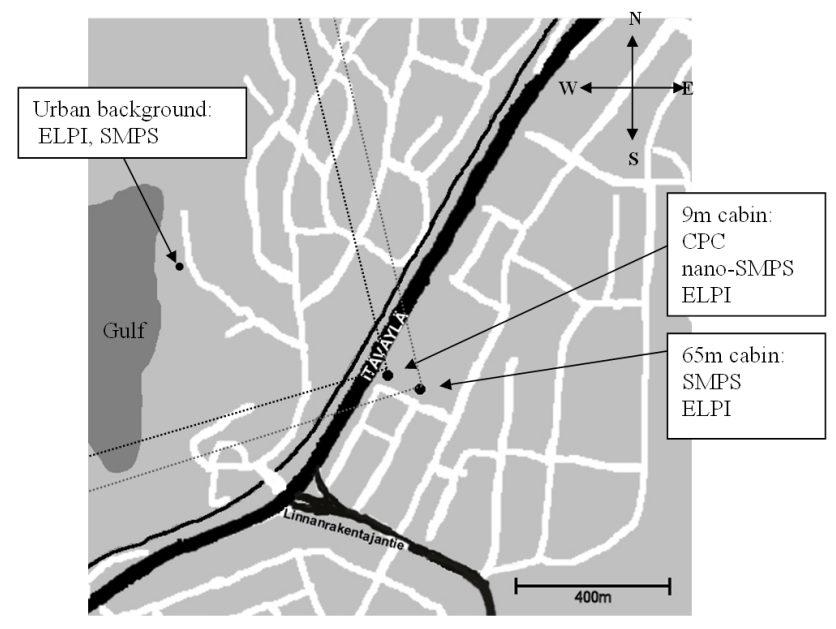

Fig. 1. Map of the measurement site. Studied wind sectors $\left(255^{\circ}-\right.$ $345^{\circ}$ ) marked with dashed lines.

\subsection{Traffic count}

A traffic count was performed at the Itäväylä highway by the City of Helsinki and the Finnish Road Administration by an automatic traffic measurement system, located some $3 \mathrm{~km}$ from the measurement site towards city centre. The continuous long-term traffic rate measurement provides hourly averages. Traffic in both directions was calculated separately. In addition, the number of heavy-duty vehicles was determined by the measurement system. We made occasional short-term (three-minute) vehicle counts to check the correlation with the continuous measurements. As reported earlier, the agreement was excellent, indicating that the continuous measurement is representative also to the traffic at the measurement location (Pirjola et al., 2006).

\subsection{Meteorological conditions}

Meteorological data (wind speed, wind direction, temperature and relative humidity) were measured at the $9 \mathrm{~m}$ cabin with a Vaisala weather station (Milos500, Vaisala). The maximum, minimum and average values for temperature and relative humidity values are shown in Table 1, together with average values for the day-time (i.e. 06:00-20:00). The meteorological conditions during the summer and winter campaigns are typical for summer and winter seasons in Helsinki.

The data were classified according to wind direction, similar to the method by Pirjola et al. (2006). This paper concentrates on the results of wind sector $\mathrm{S} 1$, which consists of wind directions $255^{\circ}-345^{\circ}$ (wind blowing from the road to the measurement cabins). The wind sector is marked in Fig. 1 with dashed lines. 
Table 1. Maximum, minimum and average values of temperature and relative humidity during the winter and summer campaigns.

\begin{tabular}{lcccccccc}
\hline & \multicolumn{2}{c}{$\mathrm{T}\left({ }^{\circ} \mathrm{C}\right)$} & \multicolumn{2}{c}{ Average } & \multicolumn{2}{c}{$R H(\%)$} & \multicolumn{2}{c}{ Average } \\
& $\max$ & $\min$ & all & day & $\max$ & $\min$ & all & day \\
\hline Summer 2003 & 22.0 & 7.0 & 15.7 & 16.4 & 98 & 43 & 79.0 & 76.1 \\
Summer 2004 & 22.0 & 7.0 & 15.4 & 16.0 & 98 & 42 & 78.7 & 74.7 \\
Winter 2003 & 5.1 & -15.2 & -3.3 & -2.8 & 98 & 51 & 85.6 & 84.0 \\
Winter 2004 & 3 & -17.8 & -4.9 & -4.9 & 98 & 55 & 86.9 & 86.3 \\
\hline
\end{tabular}

\section{Method for estimating particle density}

Particle density was estimated using the parallel measurement method described by Ristimäki et al. (2002) and Virtanen et al. (2004a). The method is based on simultaneous ("parallel") distribution measurement with ELPI and SMPS and further on the relationship between particle aerodynamic size, mobility size and effective density. The basic idea is to minimize the difference of the measured ELPI currents and currents simulated by using SMPS number distribution and ELPI response functions (i.e. the charger efficiency and impactor kernel functions). The minimization is made by altering the particle density. It should be noted that number distribution is not calculated from measured currents at any point, but instead a mathematical model of ELPI is used. The complete set of information required to construct the mathematical model of ELPI, can be found from Marjamäki et al. (2000, 2005) and Virtanen et al. (2001).

To be able to apply the parallel method in roadside particle studies the method was modified to be suitable for multimodal distributions. In the multimodal modification, the lognormal distributions are fitted into the measured SMPS data. These fitted lognormal distributions are then used in ELPI current simulation instead of measured SMPS distributions. The fitting is done by assuming a maximum 3 modes in the SMPS measurement range $(5 \mathrm{~nm}-160 \mathrm{~nm})$. To limit the degrees of freedom in the density search procedure, a constant density is assumed within each mode. The main difference to the single mode case (Ristimäki et al., 2002) is that instead of one effective density, the effective density for each sub-mode is searched. This means that the search algorithm has to operate in multi-dimensional space and the result may be more sensitive to the start point than with the single mode case. We have initialized the effective densities with an ad hoc method where the initial effective densities are suggested in a sequence starting from the mode producing the highest simulated ELPI current. The actual initialisation of each sub-distribution is performed by choosing from a set of preselected densities ranging from 0.1 to $10 \mathrm{~g} / \mathrm{cm}^{3}$. After the initialisation the search algorithm minimises the difference between the measured and simulated ELPI currents by changing the effective densities of each sub-distribution. As a result, the average density of each mode is found. We have utilised the "fminsearch" function of Matlab ${ }^{\circledR}$ to perform the minimisation. The method can be used for the ELPI and SMPS data at hand if the impactor individual and charger as well as DMA are carefully calibrated.

The method was tested in the laboratory for bimodal size distribution using two test oils as the particle material: Fomblin (perfluorinated polyether inert fluid, Ausimont Ltd) and di-octyl sebacate (DOS). The density of Fomblin is $1.9 \mathrm{~g} / \mathrm{cm}^{3}$ and the density of DOS is $0.91 \mathrm{~g} / \mathrm{cm}^{3}$. Bimodal distributions with one mode consisting of Fomblin and the other of DOS were generated using a tube furnace for Fomblin and a nebulizer with condensation-evaporation cycle for DOS. The geometric mean diameters of DOS distributions were varied between $40-50 \mathrm{~nm}$ and of the Fomblin distributions between $90-150 \mathrm{~nm}$. The method produced density estimates of $0.8 \pm 0.08 \mathrm{~g} / \mathrm{cm}^{3}$ and $1.8 \pm 0.26 \mathrm{~g} / \mathrm{cm}^{3}$ for DOS and Fomblin, respectively. These values are within $15 \%$ of the true bulk densities.

\section{Results}

\subsection{Correlation of particle emissions and traffic rate}

All the results concerning traffic rate and particle concentrations presented in this section were obtained at wind directions S1 during the weekdays (Monday-Friday). Although both winter and summer measurement periods were relatively short, the meteorological conditions and traffic rates were typical for the season. Therefore the results are believed to represent typical particle population at the roadside of Itäväylä.

In comparison to the Finnish average values, the traffic rate at Itäväylä is high. The day-time (06:00-20:00) average traffic rate was 3290 vehicles/hour during the summer campaigns and 2910 vehicles/hour during the winter campaigns. These values represent well the long-term average values for the traffic rate at Itäväylä. The average values for traffic rate measured during the campaigns are presented in Fig. 2b. The traffic rate peaked during the morning and evening rush hours i.e. 06:00-10:00 and 15:00-18:00. During the rush hours, the traffic rate reached $\sim 4000$ vehicles/hour but the traffic was fluent, not jamming. There was no remarkable difference 
between the traffic rates during the winter and summer campaigns or between the morning and evening rush hours.

Figure 2a shows the particle concentrations at the $9 \mathrm{~m}$ distance from the road, measured with CPC. The roadside concentrations followed the same temporal pattern as the traffic rate. Hussein et al. (2004) give the same hours for the minimum (03:00) and maximum (07:00) concentrations measured at the urban background stations located at Kumpula and Siltavuori in Helsinki. The minimum concentration values at the roadside were of the same order as the urban background values. No continuous background data were available. Instead, the average background concentration was calculated from several short-time measurements made by the mobile laboratory. The number of background measurement days was 17 during the summer campaigns and 11 during the winter campaigns. The time periods during which the background measurements took place were between 07:0010:00 and 14:00-20:00. The average nighttime background concentrations, calculated using short-time measurements, were $\sim 6000 \# / \mathrm{cm}^{3}$ and $10000 \# / \mathrm{cm}^{3}$ for summer and winter, respectively. Hussein et al. (2004) reported rather similar nighttime background concentration values of $8000 \# / \mathrm{cm}^{3}$ and $10000 \# / \mathrm{cm}^{3}$ during the summer and winter seasons, respectively. The average daytime background concentrations are shown by the dashed lines in Fig. 2 a.

Hussein et al. (2004) reported maximum morning rush hour concentrations of approximately $25000 \# / \mathrm{cm}^{3}$ and $17500 \# / \mathrm{cm}^{3}$, during the summer and winter seasons, correspondingly. As expected, the roadside concentrations during the morning rush hours at Itäväylä were much higher, averaging approximately $100000 \# / \mathrm{cm}^{3}$ in the winter and $50000 \# / \mathrm{cm}^{3}$ in the summer. In the winter time the concentration peaking was a bit stronger during the morning rush hours than during evening rush hours. Williams et al. (2000), Molnár et al. (2002), Wehner et al. (2002), Charron and Harrison (2003), and Janhäll et al. (2004) observed stronger concentration peaks during the morning rush hour. Wehner et al. associated the higher morning concentrations with the higher truck traffic rate. Molnár et al. attributed their results to higher wind speeds and more effective vertical mixing during the afternoons. In the case of Itäväylä, there was no difference in portion of heavy duty traffic during the morning and evening rush hours. Neither was there any remarkable difference in wind speed (in winter). We assume that the effect can be explained mostly by reduced vertical mixing in winter mornings.

The winter concentrations were approximately double compared to the summer concentrations. This can be seen in Fig. 3, where particle concentrations are presented as a function of traffic rate. The daytime background concentrations are again marked with dashed gray lines. All data points with traffic rate less than 1000 vehicles/hour were measured during nighttime. Both the summer and wintertime total concentrations increased with increasing traffic rate. A best fit to the data points was found to obey the form $y \sim x^{a}$, where $y$ is

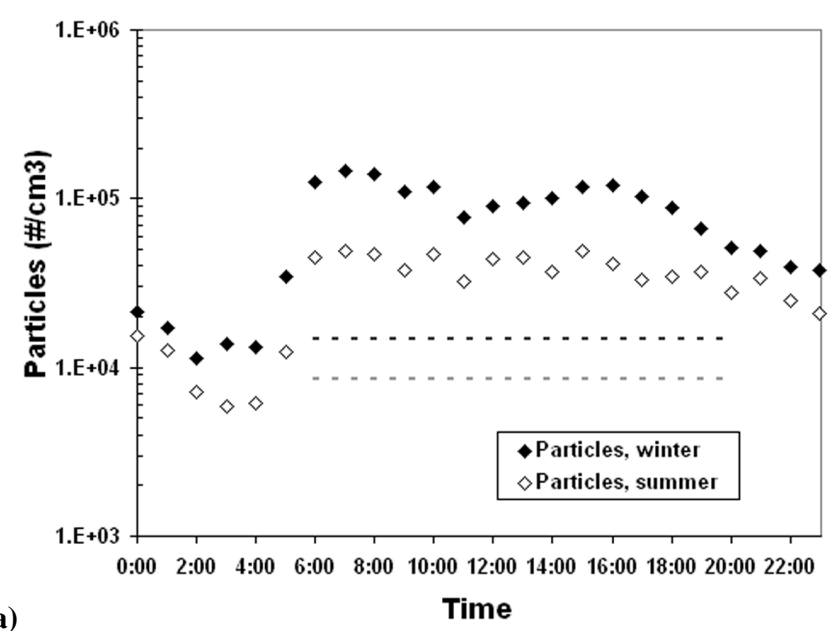

(a)

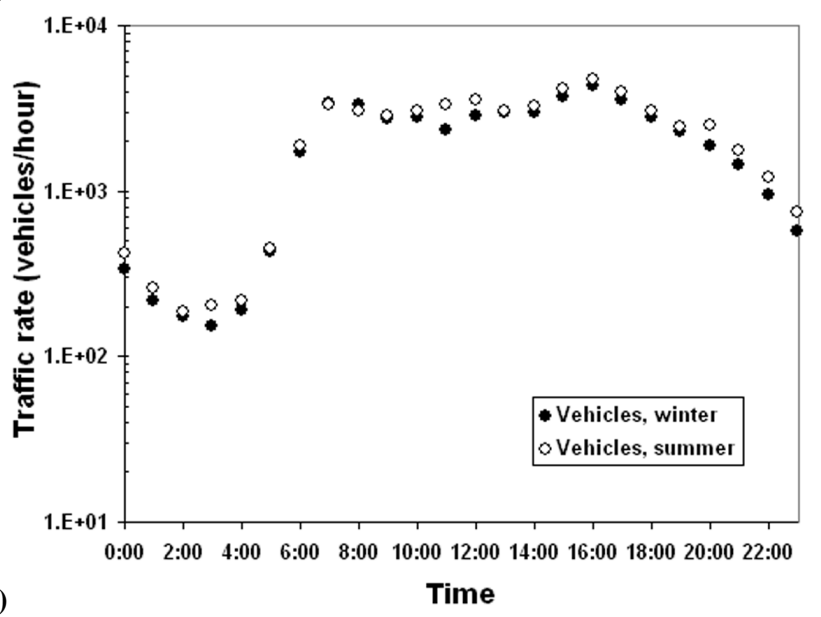

Fig. 2. (a) Measured particle concentrations ( $9 \mathrm{~m}$ distance from the road edge) and (b) traffic rates in summer and wintertime. Dashed lines in (a) represent the daytime averages for urban background (dark line for winter and light line for summer).

particle concentration and $x$ is traffic rate. The exponent " $a$ " has value 0.62 and 0.69 for summer and wintertime results, respectively (Table 2.). We believe that the non-linear dependence of the concentration on traffic rate can be explained by a combination of linear source term and time dependent urban background.

To find out the relationship between different particle size fractions and traffic rate the particles were separated into two size classes based on the cut-point of the impactor stage 2 of ELPI, $63 \mathrm{~nm}$ (in aerodynamic size). The concentration of the particles in the size fraction of $63 \mathrm{~nm}-6.6 \mu \mathrm{m}$ was calculated from ELPI distribution by integrating the particle concentrations measured on stages $2-11$. This size range is referred further as " $\mathrm{d}_{p}>63 \mathrm{~nm}$ ". The concentrations of particles smaller than $63 \mathrm{~nm}$ were calculated by subtracting the concentrations of $63 \mathrm{~nm}-6.6 \mu \mathrm{m}$ particles from the total number concentrations measured by CPC. The CPC 
Table 2. The " $a$ " values of the function $y \sim x^{a}$, where $y$ is particle concentration and $x$ is traffic flow. The " $a$ " and $\mathrm{R}^{2}$ values for total concentration and concentration of two size fractions for the summer and wintertime data are presented in the table.

\begin{tabular}{llll}
\hline$y \sim x^{a}$ & & $a$ & $\mathrm{R}^{2}$ \\
\hline Total concentration & summer & 0.62 & 0.70 \\
& winter & 0.69 & 0.81 \\
$7 \mathrm{~nm} \leq \mathrm{dp}<63 \mathrm{~nm}$ & summer & 0.60 & 0.63 \\
& winter & 0.71 & 0.83 \\
$63 \mathrm{~nm} \leq \mathrm{dp}<6.6 \mu \mathrm{m}$ & summer & 0.49 & 0.60 \\
& winter & 0.50 & 0.60 \\
\hline
\end{tabular}

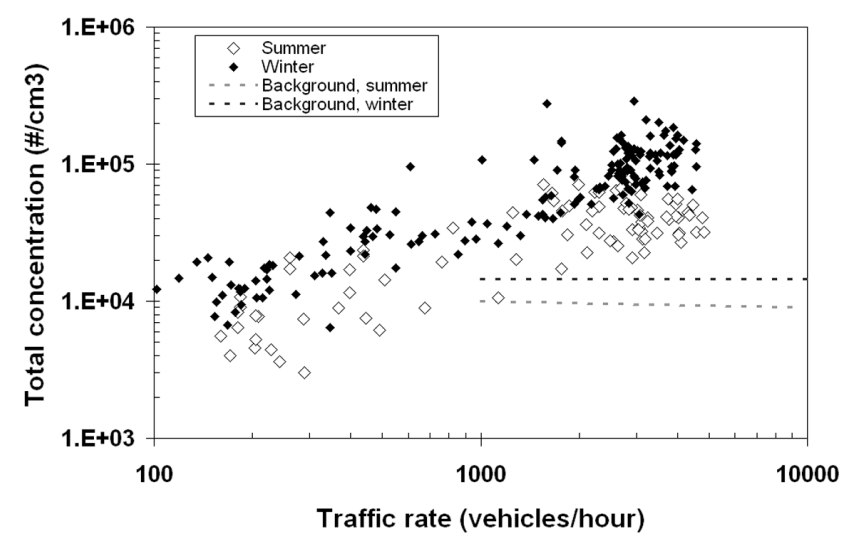

Fig. 3. Particle concentrations as a function of traffic rate. $(9 \mathrm{~m}$ distance from the road edge).

detection limit $(\sim 3 \mathrm{~nm})$ gives the lower size limit of this smaller size fraction. This size fraction is referred further as " $\mathrm{d}_{p}<63 \mathrm{~nm}$ ".

In Figs. $4 \mathrm{a}$ and $\mathrm{b}$, the concentrations of the two particle size classes $(\mathrm{dp}<63 \mathrm{~nm}$ and $\mathrm{dp}>63 \mathrm{~nm})$ are presented as a function of traffic rate. In Fig. $4 a$, the summer and winter concentrations for $d_{p}<63 \mathrm{~nm}$ particles are presented. These particles are mostly nucleation mode particles formed during the dilution process in the exhaust plume. In addition, part of the traffic related soot particles belongs to this size fraction. Also a part of the Aitken mode, which is characteristic to urban background, is in this size range (Hussein et al., 2004). In Fig. $4 \mathrm{~b}$ the concentration of particles larger than $63 \mathrm{~nm}$ is presented. These larger particles contain the traffic related soot particles with volatile materials condensed on them. In addition, this size range contains Aitken mode particles and aged, non-traffic related accumulation mode particles (Longley et al., 2004; Molnár et al., 2002). The fraction of aged accumulation mode particles can be remarkable especially when the traffic rate is low.

For both size fractions the dependence of concentration (y) on traffic rate (x) is of form $y \sim x^{a}$ as it was for the total

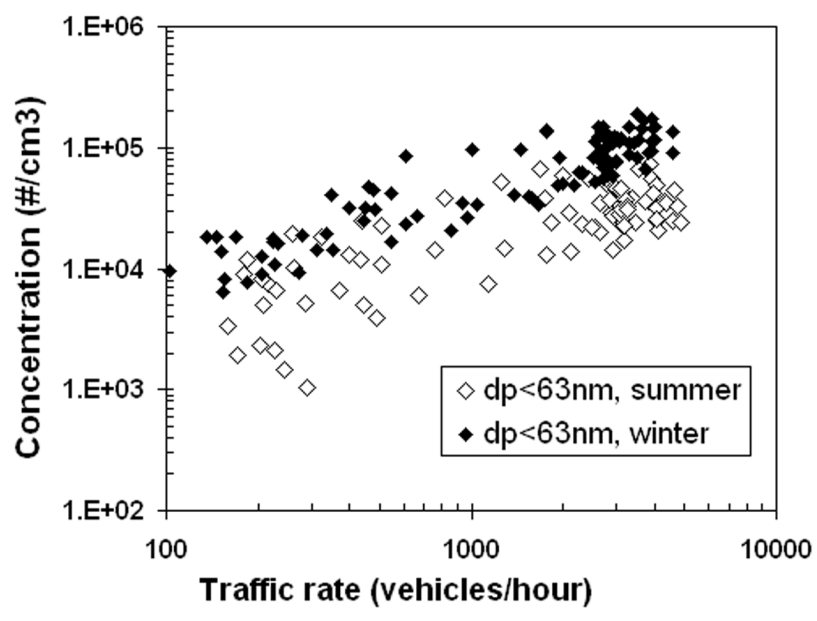

(a)

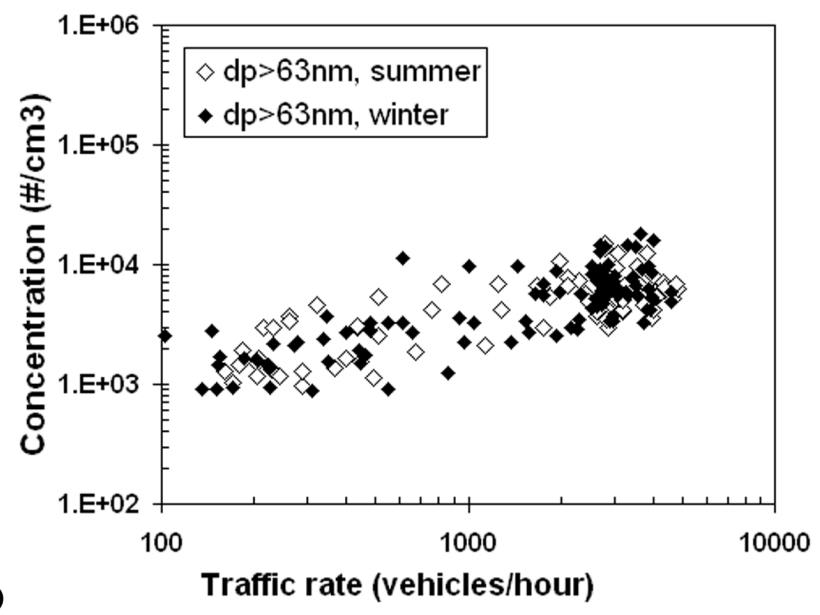

Fig. 4. Concentrations of two different size fractions as a function of traffic rate: (a) particles smaller than $63 \mathrm{~nm}$ (b) particles larger than $63 \mathrm{~nm}$. (9 $\mathrm{m}$ distance from the road edge).

concentration. The " $a$ " and $\mathrm{R}^{2}$ values are presented in Table 2 . The exponent " $a$ " has the same value for total concentration and $\mathrm{d}_{p}<63 \mathrm{~nm}$ particle concentration. This is because the concentration of $\mathrm{d}_{p}<63 \mathrm{~nm}$ particles dominated the total particle concentration: the $\mathrm{d}_{p}<63 \mathrm{~nm}$ particles constituted $\sim 90 \%$ of particles in winter time and $\sim 80 \%$ of particles in summer time. The exponent $a$ is higher for the smaller size fraction, indicating a lower contribution of the urban background aerosol. The exponent $a$ for $\mathrm{d}_{p}<63 \mathrm{~nm}$ particles is lower in the summer than in the winter. This is believed to be caused by the lower concentrations during the summer that leads to a higher relative contribution of the urban background. On the other hand, there is no seasonal difference in the exponent for the larger size fraction. Although the role of the background in this size fraction is higher, its relative contribution has less seasonal variation.

Figures $4 \mathrm{a}$ and $\mathrm{b}$ indicate that the winter concentration of $\mathrm{d}_{p}<63 \mathrm{~nm}$ particles was approximately doubled compared to 


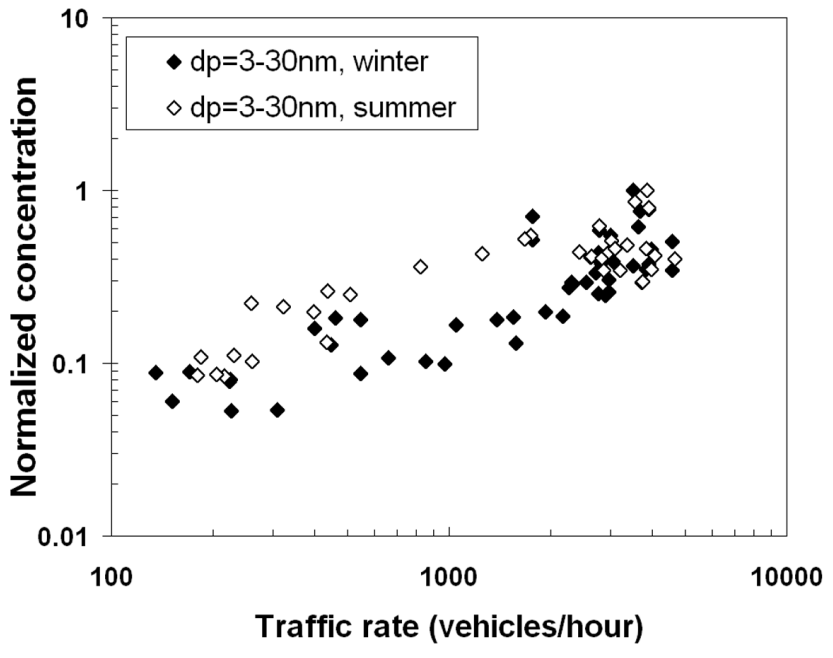

Fig. 5. The dependence of nucleation mode particle $(\mathrm{dp}=3-30 \mathrm{~nm})$ concentration on traffic rate.

the summer concentration while there was no clear seasonal difference in the concentration of $\mathrm{d}_{p}>63 \mathrm{~nm}$ particles. The difference in seasonal behavior of these two sized fractions is related to their formation mechanisms. The soot particles are formed during the combustion. According the laboratory studies by Ristimäki et al. (2005), the temperature of the engine intake air has only a minor effect on the soot particle concentration even if the intake air temperature is below $0^{\circ} \mathrm{C}$. Thus, the soot formation seems to be insensitive to the temperature of the surrounding air. On the other hand, the formation of nucleation mode particles is sensitive to dilution conditions, such as temperature and relative humidity of the surrounding air. According to Kittelson et al. (2000), low ambient temperatures favor nucleation in vehicle exhaust. In the laboratory, Ristimäki et al. (2005) found that the effect of dilution temperature depends on vehicle technology, but in most cases reported modestly increased nucleation mode formation by low dilution temperatures.

We assume that the lower temperature in the wintertime is the main reason for the number concentration of $\mathrm{d}_{p}<63 \mathrm{~nm}$ particles being higher in winter than in summer time. The smaller height of the mixing layer in winter time could, in principle, result in higher particle concentration. However, we believe that when measuring this close to the source, the vertical mixing process has not yet affected that much and the temperature plays a stronger role. It is not fully clear how the vertical mixing process of planetary boundary layer air actually affects different particle sizes. Somewhat surprisingly, the number concentrations of $d_{p}>63 \mathrm{~nm}$ particles were fairly equal when winter and summer times are compared. This agrees with the result of Hussein at al. (2004) who, in their urban measurement site in downtown Helsinki, also observed rather equal accumulation number concentrations in winter and in summer. We believe that the effect of

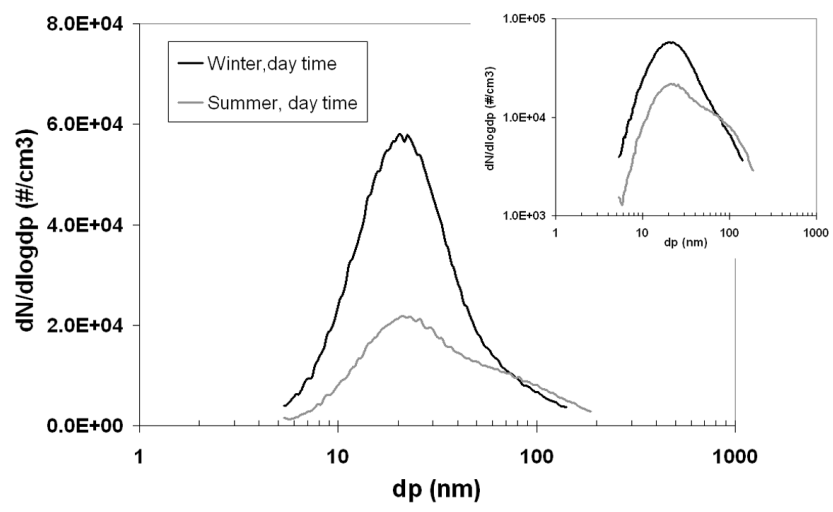

Fig. 6. Typical SMPS size distributions measured during rush hours in the winter (black line) and summer (light line). Distributions in $\log -\log$ scale are presented in the upper corner. $(65 \mathrm{~m}$ distance from the road edge).

the vertical mixing process on the fine particle size distribution is a challenging topic, and should be studied in more detail and in a larger context in forthcoming research on urban aerosol.

The nano-SMPS data measured at $9 \mathrm{~m}$ could not be used in the number concentration comparison for size fractions, because the nano-SMPS concentrations were much lower than the CPC concentrations. The difference could not be explained by the narrow measurement range of nano-SMPS (3-60 nm). Distributions measured with the "long-SMPS" at $65 \mathrm{~m}$ (see Fig. 6) show that the total concentration should be overwhelmingly dominated by particles within the nanoSMPS range. This indicates a user error in the nano-SMPS measurement. However, the nano-SMPS size distribution compared nicely with the long-SMPS at $65 \mathrm{~m}$. Therefore, the nano-SMPS data were still used to study the dependence of the nucleation mode $\left(\mathrm{d}_{p}=3-30 \mathrm{~nm}\right)$ particle concentration on traffic rate. The concentration relative to the maximum measured concentration is plotted in Fig. 5. Because of the low number of data points, no trend line was fitted, but the concentration dependence on traffic rate was similar to that of total concentration shown in Fig. 3.

\subsection{Characteristics of road-side distributions}

In Fig. 6, the average SMPS size distributions for winter and summer time rush hours are shown. All the results presented in this chapter were calculated from the data measured at the $65 \mathrm{~m}$ cabin, because it was equipped with the long-SMPS with a size range of 5-160 nm. Figure 6 shows that both distributions were dominated by small, probably nucleation originated particles with a peak size of approximately $20 \mathrm{~nm}$. Similar observation was also reported by Wehner and Wiedensohler (2003) and Ketzel et al. (2004). Multimodal lognormal distribution was fitted to the measured distributions to enable the particle density calculation 
Table 3. The daytime (06:00-20:00) summer and winter average values of distribution characteristics (geometric mean diameter GMD, geometric standard deviation GSD and number concentration $\mathrm{N}$ ) and average density $(\rho)$ of particles in the modes. (Distance $65 \mathrm{~m}$ from the road.)

\begin{tabular}{lllllllll}
\hline & $\begin{array}{l}\text { Mode 1 } \\
\text { GMD }(\mathrm{nm})\end{array}$ & GSD & $\mathrm{N}\left(\# / \mathrm{cm}^{3}\right)$ & $\rho\left(\mathrm{g} / \mathrm{cm}^{3}\right)$ & $\begin{array}{l}\text { Mode 2 } \\
\text { GMD }(\mathrm{nm})\end{array}$ & GSD & $\mathrm{N}\left(\# / \mathrm{cm}^{3}\right)$ & $\rho\left(\mathrm{g} / \mathrm{cm}^{3}\right)$ \\
\hline $\begin{array}{l}\text { Summer } \\
\text { Average }\end{array}$ & 20.3 & 1.7 & 18960 & 1.04 & 72.0 & 1.8 & 13750 & 1.5 \\
Stdev (\%) & 13.5 & 6.2 & 77.3 & 13.3 & 19.8 & 9.6 & 56.9 & 6.6 \\
Winter & & & & & & & & \\
Average & 18.9 & 1.7 & 61310 & 0.96 & 75.1 & 1.6 & 6810 & 1.8 \\
Stdev (\%) & 9.4 & 4.9 & 44.7 & 7.2 & 19.5 & 12.6 & 72.6 & 16.2 \\
\hline
\end{tabular}

procedure described above. At most of the cases, two lognormal modes were found in the distributions. These are marked as "Mode 1" and Mode 2" in Table 3 where the average values of daytime (i.e. 06:00-20:00) results are shown. Only in a few cases was a third mode found, above $110 \mathrm{~nm}$. It should be noted here, that only the modes for which the density values were found are accepted as results. If the concentration of a certain mode is low compared to other found modes, the simulated current caused by that mode is negligible compared to the total current. In this case, the density value cannot be found at all or its value can be unreasonable. Hussein et al. (2004) found mostly 3 modes in Helsinki: average geometric mean diameter (GMD) of nucleation mode was at $\sim 10-15 \mathrm{~nm}$, Aitken mode at $40-50 \mathrm{~nm}$ and accumulation mode at $\sim 150 \mathrm{~nm}$. Their measurement sites were at Kumpula and Siltavuori, representing background sites rather than roadside sites. The concentration values were significantly lower (approximately one fourth) than those reported in this study and the traffic related particle emissions were mixed into a more aged urban background. At the roadside, the distribution is dominated by fresh traffic related particles i.e. fresh nucleation mode particles and soot particles.

As shown in Table 3, the average geometric mean diameter (GMD) of traffic related nucleation mode (Mode 1) was $20.3 \pm 2.7 \mathrm{~nm}$ during the summer and $18.9 \pm 1.8 \mathrm{~nm}$ during the winter. The geometric standard deviation (GSD) value for the nucleation mode was 1.7 both for the summer and winter. Imhof et al. (2005b) measured particle size distributions in two different road tunnels in Graz and Liverpool. They found nucleation mode with GMDs around $15-20 \mathrm{~nm}$ in Graz and $25 \mathrm{~nm}$ in Liverpool and GSDs of approximately 1.8 and 1.5 respectively. These values are in good agreement with our study. Ketzel et al. (2004) found that the traffic related distributions peaked at $22 \mathrm{~nm}$ in the centre of Copenhagen. In addition, Wehner and Wiedensohler (2003) reported the peak in the urban number size distribution around $20 \mathrm{~nm}$. They also found the additional mode peaking at $10-15 \mathrm{~nm}$ during the summer time. This mode was related to the new particle formation event that correlated with the amount of global radiation. During our measurement campaigns we observed only two similar formation event days during the summer campaign 2004. This data were omitted from results. In the laboratory and chase measurements the nucleation mode existence and peak diameter show great variation (Kittelson et al., 2004; Vaaraslahti et al., 2004; Rönkkö et al., 2006). The reported traffic related nucleation mode GMDs measured in roadside or traffic tunnel have a surprisingly constant values close to $20 \mathrm{~nm}$.

The GMD of Mode 2 was $72.0 \pm 14.3 \mathrm{~nm}$ in the summer and $75.1 \pm 14.6 \mathrm{~nm}$ in the winter, while the GSD was 1.8 and 1.6 in summer and in winter, respectively. Imhof et al. (2005b) measured the road tunnel soot distributions peaking at around $80-100 \mathrm{~nm}(\mathrm{GSD} \sim 1.85)$ in the tunnel in Graz. On the other hand, they reported that the soot mode measured in the traffic tunnel in Liverpool was not clearly distinguishable in the distribution and its GMD was around $45 \mathrm{~nm}$ (GSD 2.22). Rose et al. (2005) studied the soot particle distribution in a street canyon in Leipzig. They observed the soot distribution peaking at $65 \mathrm{~nm}$ and $70 \mathrm{~nm}$ during the summer and winter. They also found that the soot particles make up $50-60 \%$ of the number of $80 \mathrm{~nm}$ particles at the roadside. In the urban background the corresponding percentile is $20-25 \%$. In addition, the GMD values for the soot mode of single vehicle emissions are reported to be typically $50-90 \mathrm{~nm}$ and GSD values around 1.8 (e.g. Harris and Maricq, 2001). According to the above, the GMD and GSD values of Mode 2 were controlled by the traffic related soot particles. This is not necessarily so in a more polluted environment. Mönkkönen et al. (2005) studied mode characteristics in a polluted Asian mega city. The GMD of nucleation mode was smaller, most of the time below $10 \mathrm{~nm}$. The distributions were dominated by Aitken and accumulation modes with GMD values of 30-60 nm and 120-160 nm, respectively. The different mode characteristics are probably related to other particle sources than traffic.

In Fig. 7, the GMD values of fitted distributions are shown as a function of traffic rate. The GMD of nucleation mode and accumulation mode seems to be rather independent on 
traffic rate. At traffic rate values $<500$ vehicles/hour (i.e. night time measurements), the GMD of both modes seem to increase. This is caused by the diminishing portion of traffic related particles in the particle population. In this case the urban background i.e. Aitken and accumulation modes become dominant modes in the measured distribution. In fact, the fitted GMD values at low traffic rates were $30-40 \mathrm{~nm}$ and $80-140 \mathrm{~nm}$, in accordance with the values measured both at the urban and rural background stations (e.g. Tunved et al., 2003; Hussein et al., 2004).

\subsection{Particle density}

Table 3 also shows the density values corresponding to the two modes. The density of "Mode 1", i.e. nucleation mode, is $1.04 \pm 0.14 \mathrm{~g} / \mathrm{cm}^{3}$ and $0.96 \pm 0.07 \mathrm{~g} / \mathrm{cm}^{3}$ during the summer and winter time, respectively. There are no published data for the density of traffic related nucleation mode particles. Sakurai et al. (2003a) analyzed the composition of nucleation particles emitted from heavy-duty diesel engine without any after-treatment systems. They found that the particles consist of organic compounds with a carbon number of 24-32. Sakurai et al. (2003b) estimated a density of $0.8 \mathrm{~g} / \mathrm{cm}^{3}$ for these compounds. In addition, the nucleation mode formation is connected to the sulphate formation, especially when oxidation catalyst is used (Lepperhof, 2001; Maricq et al., 2002; Vaaraslahti et al., 2004). According to studies of Vogt et al.(2003); Gieshaskiel et al. (2005) the sulphuric acid water nucleation seems to have an important role in the nucleation mode formation. This would produce particles with a density somewhere below that of sulphuric acid, $1.8 \mathrm{~g} / \mathrm{cm}^{3}$. The present density values fit nicely into this general scheme.

The found effective density value for "Mode 2" was $1.45 \pm 0.10 \mathrm{~g} / \mathrm{cm}^{3}$ and $1.87 \pm 0.30 \mathrm{~g} / \mathrm{cm}^{3}$ for summer and wintertime, respectively. The results are in good agreement with the study of McMurry et al. (2002). They found that the density of $\sim 0.1 \mu \mathrm{m}$ urban aerosol particles measured in Atlanta, USA, varied between $\sim 1.4-1.7 \mathrm{~g} / \mathrm{cm}^{3}$. The density values found in this and previous studies are high compared to the reported values for soot particle densities. According to the laboratory studies of Park et al. (2003); Virtanen et al. (2004b) and Maricq et al. (2004) the density of the porous diesel soot agglomerates is close to $1 \mathrm{~g} / \mathrm{cm}^{3}$ at $\sim 60 \mathrm{~nm}$ and below $\sim 0.6 \mathrm{~g} / \mathrm{cm}^{3}$ at $\sim 100 \mathrm{~nm}$. If the voids in the agglomerated particles get filled with condensable materials, particle density increases. It is still unlikely that the condensation of volatiles could increase the density of soot particles in "Mode 2" up to $1.4-1.8 \mathrm{~g} / \mathrm{cm}^{3}$. It is more probable that the mode is an external mix of soot particles and urban background particles of other materials. The found density for "Mode 2" is the average density for the mixed aerosol. In fact the relatively low increase of concentration of particles larger than $63 \mathrm{~nm}$ with increasing traffic rate (see Fig. 4 and Table 2) and the results of Rose et al. (2005) discussed above

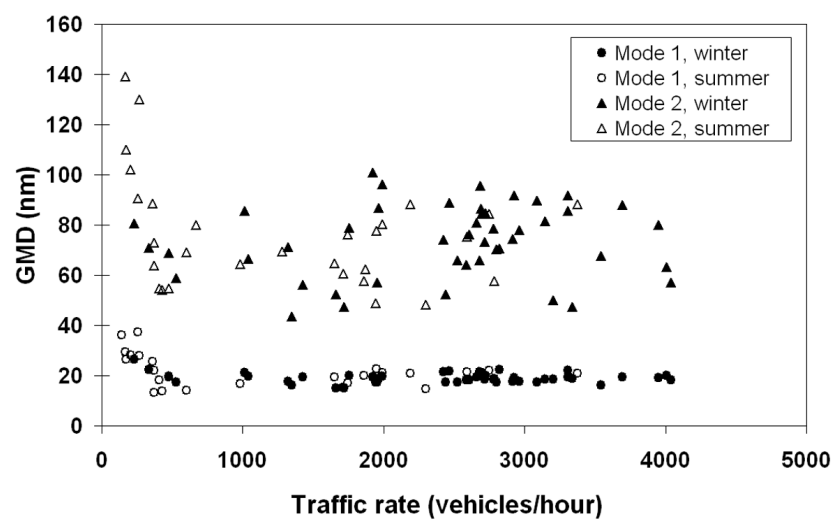

Fig. 7. Geometric mean diameters of "Mode 1" and "Mode 2" as a function of traffic rate. (65 $\mathrm{m}$ distance from the road edge).

supports the assumption that a significant portion of particles in "Mode 2" are not fresh vehicle emitted particles.

\section{Conclusions}

The total concentrations at roadside were dominated by nucleation mode particles. The concentrations were 2-3 times higher in the wintertime than in the summer time. Particles smaller than $63 \mathrm{~nm}$ in aerodynamic diameter made up $\sim 90 \%$ of particles in the winter and $\sim 80 \%$ of particles in summer. The number concentrations of particles increased with increasing traffic rate. The effect of traffic rate on particles smaller than $63 \mathrm{~nm}$ was stronger than on the larger particles.

Particle size distribution at the roadside consisted of two distinguishable modes. The GMD of the nucleation mode (Mode 1) at $65 \mathrm{~m}$ distance from the road was $20.3 \mathrm{~nm}$ in the summer and $18.9 \mathrm{~nm}$ in winter. The GMD of the nucleation mode was independent of the traffic rate. The average density value for Mode 1 particles was $\sim 1.0 \mathrm{~g} / \mathrm{cm}^{3}$ both in the summer and winter. All these values are close to those expected from exhaust measurements for the nucleation mode. It is concluded that this mode is totally controlled by the fresh vehicle emissions.

The GMD of the larger mode (Mode 2) was $72.0 \mathrm{~nm}$ in the summer and $75.1 \mathrm{~nm}$ in the winter. These values correspond to soot mode emissions. However, the average density value for Mode 2 was $1.5 \pm 0.1 \mathrm{~g} / \mathrm{cm}^{3}$ in the summer and $1.8 \pm 0.3 \mathrm{~g} / \mathrm{cm}^{3}$ in winter, which is considerably higher than expected from the soot mode exhaust studies. This indicates a higher contribution of the urban background to this externally mixed mode.

Acknowledgements. The study has been funded by Fine - program of Finnish Technology Agency (Tekes) and Maj and Tor Nessling foundation.

Edited by: U. Pöschl 


\section{References}

Abdul-Khalek, I. S., Kittelson, D. B., and Brear, F.: The influence of dilution conditions on diesel exhaust particle size distribution measurements, SAE technical paper series, no. 1999-01-1142, 1999.

Charron, A. and Harrison, R. M.: Primary particle formation from vehicle emissions during exhaust dilution in the roadside atmosphere, Atmos. Environ., 37, 4109-4119, 2003.

Gieshaskiel, B., Ntziachristos, L., Samaras, Z., Scheer, V., Casati, R., and Vogt, R.: Formation potential of vehicle exhaust nucleation mode particles on-road and in the laboratory, Atmos. Environ., 39, 3191-3198, 2005.

Harris, S. J. and Maricq, M. M.: Signature size distribution for diesel and gasoline engine exhaust particulate matter, J. Aerosol Sci., 32, 749-764, 2001.

Hussein, T., Puustinen, A., Aalto, P. P., Mäkelä, J. M., Hämeri, K., and Kulmala, M.: Urban aerosol number size distributions, Atmos. Chem. Phys., 4, 391-411, 2004, http://www.atmos-chemphys.net/4/391/2004/.

Imhof, D., Weingartner, E., Ordóñez, C.,Gehrig, R., Hill, M., Buchmann, B., and Baltensberger, U.: Real-world emission factors of fine and ultra fine aerosol particles for different traffic situations in Switzerland, Environ. Sci. Technol., 39, 8341-8350, 2005a.

Imhof, D., Weingartner, E., Prévöt, A. S. H., Ordóñez, C., Kurtenbach, R., Wiesen, P., Rodler, J., Sturm, P., McCrae, I., Sjödin, Å., and Baltensberger, U.: Aerosol and NOx emission factors and submicron particle number size distributions in two road tunnels with different traffic regimes, Atmos. Chem. Phys. Discuss., 5, 5127-5166, 2005b.

Janhäll. S., Jonsson, Å. M., Molnár, P., Svensson, E., and Hallquist, M.: Size resolved traffic emission factors of submicrometer particles, Atmos. Environ., 38, 4331-4340, 2004.

Ketzel, M., Wåhlin, P., Kristensson, A., Swietlicki, E., Berkowicz, R., Nielsen, O. J., and Palmgren, F.: Particle size distribution and particle mass measurements at urban, near-city and rural level in the Copenhagen area and Southern Sweden, Atmos. Chem. Phys., 4, 281-292, 2004, http://www.atmos-chemphys.net/4/281/2004/.

Khalek, I. A., Kittelson, D. B., and Brear, F.: Nanoparticle growth during dilution and cooling of diesel exhaust: experimental investigation and theoretical assessment, SAE technical paper series, No. 2000-01-0515, 2000.

Kittelson, D. B.: Engines and nanoparticles: a review, J. Aerosol Sci., 29, 575-588, 1998.

Kittelson, D., Johnson, J., Watts, W., Wei, Q., Drayton, M., Paulsen, D., and Bukowiecki, N.: Diesel aerosol sampling in the atmosphere, SAE technical paper series, No. 2000-01-22212, 2000.

Kittelson, D. B., Watts, W. F., and Johnson, J. P.: Nanoparticle emissions on Minnesota highways, Atmos. Environ., 38, 9-19, 2004.

Lepperhof, G.: Influences on the particle size distribution of diesel particulate emissions, Topics in Catalysis, 16/17(1-4), 2001.

Longley, I. D., Gallagher, M. W., Dorsey, J. R., and Flynn, M.: A case study of fine particle concentrations and fluxes measured in a busy street canyon in Manchester, UK, Atmos. Environ., 38, 3595-3603, 2004.

Maricq, M., Chase, R., Xu, N., and Laing, P.: The effects of catalytic converter and fuel sulfur level on motor vehicle particle emissions: Light duty vehicle emissions, Environ. Sci. Technol., 36, 283-289, 2002.
Maricq, M. and $\mathrm{Xu}, \mathrm{N} .:$ The effective density and fractal dimension of soot particles from premixed flames and motor vehicle exhaust, J. Aerosol Sci., 35, 1251-1274, 2004.

Marjamäki, M., Keskinen, J., Chen, D.-R., and Pui, D. Y. H.: Performance evaluation of the electrical low pressure impactor (ELPI), J. Aerosol Sci., 31(2), 249-261, 2000.

Marjamäki, M., Lemmetty, M., and Keskinen, J.: ELPI response and data reduction I: Response functions, Aerosol Sci. Technol., 39, 575-582, 2005.

McMurry, P., Wang, X., Park, K., and Ehara, K.: The relationship between mass and mobility for atmospheric particles: A new technique for measuring particle density, Aerosol Sci. Technol., 36, 227-238, 2002.

Molnár, P., Janhäll, S., and Hallquist, M.: Roadside measurements of fine and ultrafine particles at a major road north of Gothenburg, Atmos. Environ., 36, 4115-4123, 2002.

Mönkkönen, P., Koponen, I., Lehtinen, K. E. J., Hämeri, K., Uma, R., and Kulmala, M.: Measurements in a highly polluted Asian mega city: observations of aerosol number size distribution, modal parameters and nucleation events, Atmos. Chem. Phys., 5, 57-66, 2005, http://www.atmos-chem-phys.net/5/57/2005/.

Park, K., Cao, F., Kittelson, D., and McMurry, P.: Relationship between particle mass and mobility for diesel exhaust particles, Environ. Sci. Technol., 37, 577-583, 2003.

Pirjola, L., Paasonen, P., Pfeiffer, D., Hussein, T., Hämeri, K., Koskentalo, T., Virtanen, A., Rönkkö, T., Keskinen, J., and Pakkanen, T.: Dispersion of particles and trace gases nearby a city highway: mobile laboratory measurements in Finland, Atmos. Environ., 40, 867-879, 2006.

Pirjola, L., Parviainen, H., Hussein, T., Valli, A., Hämeri, K., Aalto, P., Virtanen, A., Keskinen, J., Pakkanen, T. A., Mäkelä, T., and Hillamo, R. E.: "Sniffer" - a novel tool for chasing vehicles and measuring traffic pollutants, Atmos. Environ., 38, 3625-3635, 2004.

Ristimäki, J., Virtanen, A, Marjamäki, M., Rostedt, A., and Keskinen, J.: On-line measurement of size distribution and effective density of submicron aerosol particles, J. Aerosol Sci., 33, 15411557, 2002.

Ristimäki, J., Keskinen, J., Virtanen A., Maricq, M., and Aakko, P.: Cold temperature PM emissions measurement: Method evaluation and application to light duty vehicles, Environ. Sci. Technol., 39, 9424-9430, 2005.

Rose, D., Wehner, B., Ketzel, M., Engler, C., Voigtländer, J., Tuch, T., and Wiedensohler, A.: Atmospheric number size distributions of soot particles and estimation of emission factors, Atmos. Chem. Phys., 6, 1021-1031, 2006, http://www.atmos-chemphys.net/6/1021/2006/.

Rönkkö, T., Virtanen , A., Vaaraslahti, K., Keskinen, J., Pirjola, L., and Lappi, M.: Effect of dilution conditions and driving parameters on nucleation mode particles in diesel exhaust: Laboratory and on-road study, Atmos. Environ., 40, 2893-2901, 2006.

Sakurai, H., Tobias, H., Park, K., Zarling, D., Doherty, K. S., Kittelson, D. B., McMurry, P. H., and Ziemann, P.: On-line determination of diesel nanoparticle composition and volatility, Atmos. Environ., 37, 1199-1210, 2003a.

Sakurai, H., Park, K., McMurry, P., Zarling, D. D., Kittelson, D. B., and Ziemann, P.: Size-Dependent mixing characteristics of volatile and nonvolatile components in diesel exhaust aerosols, Environ. Sci. Technol., 37, 5487-5495, 2003b. 
Stein, S. W., Turpin, B. J., Cai, X. P., Huang, P. F., and McMurry, P. H.: Measurements of relative humidity-dependent bounce and density for atmospheric particles using tandem-DMA-impactor technique, Atmos. Environ., 28, 1739-1746, 1994.

Tunved, P., Hansson, H.-C., Kulmala, M., Aalto, P., Viisanen, Y., Karlsson, H., Kristensson, A., Swietlicki, E., Dal Maso, M., and Komppula, M.: One year boundary layer aerosol size distribution data from five Nordic background stations, Atmos. Chem. Phys., 3, 2183-2205, 2003, http://www.atmos-chemphys.net/3/2183/2003/.

Vaaraslahti, K., Virtanen, A., Ristimäki, J., and Keskinen, J.: Nucleation mode formation in heavy-duty diesel exhaust with and without particulate filter, Environ. Sci. Technol., 38, 4884-4890, 2004.

Van Dingenen, R., Raes, F., Putaud, J.-P., Baltensberger, U., Charron, A., Facchini, M.-C., Decesari, S., Fuzzi, S., Gehrig, R., Hansson, H.-C., Harrison, R. M., Hüglin, R., Jones, A. M., Laj, P., Lorbeer, G., Maenhaut, W., Palmgren, F., Querol, X., Rodriquez, S., Schneider, J., ten Brink, H., Tunved, P., Torseth, K., Wehner, B., Weingartner, E., Wiedensohler, A., and Wåhlin, P.: A European aerosol phenomenology - 1: physical characteristics of particulate matter at kerbside, urban, rural and background areas in Europe, Atmos. Environ., 38, 2561-2577, 2004.

Virtanen, A., Marjamäki, M., Ristimäki, J., and Keskinen, J.: Fine particle losses in electrical low-pressure impactor, J. Aerosol Sci., 32, 389-401, 2001.
Virtanen, A., Ristimäki, J., and Keskinen, J.: Method for measuring effective density and fractal dimension of aerosol agglomerates, Aerosol Sci. Technol., 38, 437-446, 2004a.

Virtanen, A., Ristimäki, J., Vaaraslahti, K., and Keskinen J.: Effect of engine load on diesel soot particles, Environ. Sci. Technol., 38, 2551-2556, 2004b.

Vogt, R., Sheer, V., Casati, R., and Benter, T.: On-road measurement of particle emission in the exhaust plume of a diesel passenger car, Environ. Sci. Technol., 37, 4070-4076, 2003.

Wehner, B., Birmili, W., Gnauk, T., and Wiedensohler, A.: Particle number size distribution in a street canyon and their transformation into the urban air background: measurements and a simple model study, Atmos. Environ., 36, 2215-2223, 2002.

Wehner, B. and Wiedensohler, A.: Long term measurements of submicron urban aerosols: statistical analysis for correlations with meteorological conditions and trace gases, Atmos. Chem. Phys., 3, 867-879, 2003, http://www.atmos-chemphys.net/3/867/2003/.

Williams, P. I., Gallagher, M. W., Choularton, T. W., Coe, H., Bower, K. N., and McFiggans, G.: Aerosol development and interaction in an urban plume, Aerosol Sci. Technol., 32, 120-126, 2000.

Wåhlin, P., Palmgren, F., and Van Dingenen, R.: Experimental studies of ultra fine particles in streets and the relationship to traffic, Atmos. Environ., Suppl. 1, 35, 63-69, 2001. 